\title{
O Atendimento de Emergência a Corpos Feridos por Atos Violentos ${ }^{1}$
}

CYNTHIA ANDERSEN SARTI

\section{RESUMO}

A indagação fundamental deste texto diz respeito aos limites e possibilidades de uma atenção a casos de violência no âmbito da saúde, em particular na emergência. Parte-se do problema de que uma atenção especializada a esses casos requer uma atuação interdisciplinar e multiprofissional, distinta daquela pressuposta na formação biomédica que caracteriza os profissionais de saúde em geral, sobretudo médicos e enfermeiros. Com base em pesquisa etnográfica em um hospital público de emergências na cidade de São Paulo, busca-se analisar as concepções de corpo e violência desses profissionais, subjacentes a suas práticas de atendimento a corpos feridos por atos violentos, dadas as características desses serviços. Pretende-se atentar para as concepções e práticas que se instituem em um contexto de atendimento à saúde caracterizado pela destituição da subjetividade tanto dos doentes, quantos dos profissionais - da qual são emblemáticos os serviços de emergência - e discutir suas implicações para a atenção a casos de violência.

Palavras-chave: Práticas de saúde; biomedicina; atendimento à violência; emergência.

Recebido em: 29/03/2005.

Aprovado em: 06/06/2005. 


\section{1 . Introdução}

Este texto busca discutir questões acerca do atendimento em saúde a corpos feridos por atos violentos, que emergiram de pesquisa etnográfica desenvolvida em um hospital público de emergências, na cidade de São Paulo. O início da pesquisa se deve a uma demanda de assessoria na implantação de um núcleo de atenção a vítimas de violência no referido hospital, feita por sua direção².

As reflexões aqui sugeridas inscrevem-se, portanto, em duas ordens de preocupações. Uma delas é de ordem prática, acima citada, e diz respeito às possibilidades de consolidação de uma atenção específica a vítimas de violência em atendimentos de emergência; a outra é teórica, e decorre da prática interdisciplinar, que foi insinuando um descompasso entre a formação biomédica dos profissionais de saúde e as questões enfrentadas em suas práticas de trabalho - problemática que diz respeito à irredutibilidade dos fenômenos da saúde e da doença à racionalidade biológica, por se constituírem também no registro da ordem psíquica, cultural e social.

A pesquisa foi igualmente inspirada por uma discussão, desenvolvida no âmbito da filosofia da medicina (PAUL, 1998) 3 , segundo a qual há um hiato entre o conhecimento médico, baseado no modelo biomédico, e sua aplicação prática, que se transforma em problema epistemológico, a partir da indagação sobre o quê, como e quanto do conhecimento adquirido é posto em prática no ato médico, ou ato de intervenção médica sobre o corpo. A pergunta correlata que nos interessa, então, é: o que, daquilo que é posto neste ato, fica fora da formação biomédica?

A questão diz respeito aos profissionais da saúde e à interdisciplinaridade que requer o atendimento, uma vez que seu objeto transcende a dimensão biológica e, por se referir ao conhecimento no qual se baseia a prática, está implícita também, nesta questão, a indagação de Canguilhem (1995) sobre o que, na medicina, é ciência ou técnica.

A conjunção dessas preocupações levou-nos, então, a focalizar a pesquisa nos profissionais de saúde, particularmente nos médicos e enfermeiros, por serem esses profissionais os agentes diretos do discurso e das práticas biomédicas - os que vivem a experiência desse hiato -, num contexto específico, um hospital de emergências, cujo atendimento está, em grande parte, relacionado à ocorrência de violência. É pela porta dos pronto-socorros que entram os corpos feridos por atos violentos, para serem tratados e assistidos pelos profissionais da saúde. 
O foco nos profissionais funda-se, ainda, na tentativa de analisar o atendimento em saúde numa perspectiva relacional, cujos agentes (profissionais e "pacientes") estão subsumidos por uma mesma lógica, que se sustenta precisamente por ser internalizada por todos, em seus distintos lugares. Clavreul (1978), como Foucault (1977), chamou a atenção para o quanto a medicina destitui não apenas o doente de sua doença, de seu sofrimento e de sua posição subjetiva, mas destitui igualmente o médico, que se apaga subjetivamente diante das exigências de seu saber. Trataremos de pensar não em termos de uma destituição, mas, ao contrário, nas formas eficazes de instituição de pessoas, uma vez que a idéia de destituição, por sua negatividade, supõe a referência a posições instituídas. Pretendemos atentar para o que institui a "destituição da subjetividade", característica da ordem médica.

Para trabalhar essas questões, a pesquisa focaliza o atendimento aos corpos feridos por atos violentos na emergência, atentando para as concepções de corpo e de violência que subjazem às práticas de atendimento, situando-as nesse contexto específico. Apresentaremos, neste artigo, indicações do trabalho de campo a esse respeito, tendo em vista analisar os limites e as possibilidades de uma atenção especializada a vítimas de violência na emergência.

Quando se aborda a Biomedicina - ou Medicina Ocidental Contemporânea, entendida como o conjunto de conhecimentos e práticas hegemônicos no campo da saúde ${ }^{4}$ - sob o enfoque das Ciências Humanas e Sociais, evidenciam-se distintas racionalidades científicas, que estabelecem uma distância entre o sujeito e o objeto da investigação. No entanto, está implícita na escolha do objeto também uma identidade cultural, na medida em que a (Bio)medicina, por ser ocidental e contemporânea, é a referência internalizada (inconsciente, portanto) para os cuidados de muitas de nossas próprias dores, sofrimentos e perturbações.

Clavreul (1978) reconhece a dificuldade de crítica à ordem médica, uma vez que "cada um de nós é solidário demais com o discurso médico a ponto de não aderirmos de antemão a suas razões" ${ }^{5}$. Trata-se de procurar, pelo menos, evitar o que Duarte (1998, p. 23) sintetizou como as "universalizações ingênuas impostas pela não-relativização dos pressupostos ideológicos de nossa própria cultura".

A necessidade desse controle epistemológico acentua-se quando a pesquisa é desenvolvida no âmbito de uma universidade de Saúde, a partir de questões teóricas que emergem precisamente de dificuldades práticas inerentes 
à ordem médica e que demandam respostas igualmente práticas e muitas vezes urgentes. O risco a ser evitado passa a ser o de um empirismo pragmático que leve a perder o senso dos problemas (SARTI, 2003).

\section{O Problema Inicial da Pesquisa: a violência no campo da Saúde}

A introdução do tema da violência no campo da Saúde deve-se à Epidemiologia. Aconteceu sobretudo pela mudança, observada nas últimas décadas, no perfil de mortalidade e de morbidade no mundo e no país, dado o aumento de mortes e "lesões por causas externas", ao lado do maior controle médico e diminuição das doenças infecto-contagiosas (MINAYO, 1994; DESLANDES, 2002). Hoje, diante de sua alta incidência em escala mundial, a questão da violência é considerada prioridade de saúde pública, segundo resoluções da Organização Pan-americana de Saúde e da Organização Mundial da Saúd6 .

No Brasil, a partir dos anos 1980, um ativo movimento feminista e as lutas em defesa dos direitos de crianças e adolescentes - que culminaram com significativas alterações no que se refere ao estatuto legal da mulher na família e na sociedade, ampliando seus direitos civis e sociais na Constituição de 1988, e a promulgação do Estatuto da Criança e do Adolescente, em 1990 - foram forças decisivas no sentido de dar visibilidade à violência, impulsionar ações preventivas e mostrar suas conexões com a questão da saúde (MINAYO e SOUZA, 1999; OLIVEIRA, 2000).

Não é de se estranhar, portanto, que a perspectiva de gênero tenha marcado uma significativa e extensa literatura sobre violência, desde os anos 80 (ALBANO e MONTERO, 1982; ARDAILLON e DEBERT, 1987; GREGORI, 1993; GROSSI, 1994; OLIVEIRA, 2000; PONTES, 1986; SAFFIOTTI, 1999; SUAREZ e BANDEIRA, 1999). Com base nas contribuições da psicanálise, os atos violentos foram também olhados a partir do significado a eles atribuído por quem os vivencia ou presencia (COSTA, 1986; SOARES et al., 1996).

Uma nova configuração da violência urbana, na qual as principais vítimas de homicídios são os jovens pobres e negros, do sexo masculino, entre 15 e 24 anos (SOARES, 2004), trouxe novas questões para as formulações sobre gênero e raça/etnia, que contribuem para evidenciar a importância de se pensar a figura da vítima, assim como a do agressor, como construções sociais e simbólicas, reafirmando a violência como um fenômeno contextual. 
Nas Ciências Sociais brasileiras, a questão da violência tem sido analisada prioritariamente sob o prisma de sua relação com a criminalidade, como mostrou Zaluar (1999), em sua revisão da literatura. Vista a partir da área da Saúde, entretanto, a problemática da violência diz respeito a situações que não estão necessariamente enquadradas na categoria jurídica de crime, mas podem se referir a formas veladas e não nomeadas de violência, que se tornam visíveis no atendimento à saúde (exame físico); ou seja, no cuidado aos corpos feridos, sobretudo nos casos de violência doméstica ou outros casos suspeitos, cujo desvendamento envolve conflitos de várias ordens para os profissionais de saúde.

O reconhecimento e a visibilidade de atos violentos e a necessidade de medidas preventivas fizeram da violência um alvo de políticas públicas no plano tanto internacional quanto nacional e local. Dentro dessa perspectiva, como parte da política de saúde do Município de São Paulo, foi criado em agosto de 2001, o Núcleo de Atenção à Vítima de Violência (NAVV), no hospital municipal referido.

A intenção na criação do NAVV foi dar um lugar a algo que já existia e era vivenciado pelos profissionais na emergência - médicos, enfermeiros, psicólogos e assistentes sociais - que enfrentam dificuldades de várias ordens para nomeá-lo, discuti-lo e trabalhá-lo. Buscamos, assim, investigar que sentido tem a atenção à violência para os profissionais que trabalham no hospital que justifique a criação de um núcleo interdisciplinar especializado em casos de violência, no âmbito de um atendimento de emergência. A pergunta inicial foi: estaremos diante de uma iniciativa bem-intencionada, mas dissociada da realidade e das possibilidades do serviço no qual se aplica? Pergunta que coincide com aquela formulada por Deslandes (2002, p. 153), quando discute a prevenção à violência nos serviços de emergência: "é possível esperar da área da saúde e de seus profissionais mais do que a aplicação da racionalidade médicocientífica?".

\section{Violência e Doença}

A introdução da violência na área da Saúde implicou uma associação entre violência e doença, a partir do discurso epidemiológico. Assim, fala-se em uma "vigilância epidemiológica da violência" . O mesmo princípio da causalidade, que explica as doenças, fundamenta a classificação da violência nos dados epidemiológicos, definida como "lesões por causas externas" (que incluem 
fenômenos diversos, tais como "agressões" ou "acidentes"), contrapostas às "lesões autoprovocadas", quando se reconhece a intenção, declarada ou suspeita, de auto-agressão. O raciocínio causal encontra-se, assim, analogamente presente na explicação da violência, tratando indistintamente fenômenos diversos.

Perguntamos, então, se a inteligibilidade possível do fenômeno da violência, no campo da Saúde, existe na medida de sua tradução para os termos da medicina, em sua vertente epidemiológica, identificando-o com o objeto desse campo, a doença - neste mesmo sentido, Deslandes (2002) problematiza a identificação entre violência e epidemia. Tratam-se e pensam-se de forma indiferenciada ambos os fenômenos? Como se diferencia o tratamento do corpo doente e do corpo ferido por um ato violento? Como se concebem, enfim, os fenômenos da violência e da doença?

A identificação entre violência e doença remete à concepção de doença. Questão clássica para a Antropologia da doença, o foco médico na doença e não no doente acentua a universalidade em detrimento da singularidade tanto individual como cultural, problemática enunciada na Antropologia médica norteamericana, que trabalhou o fenômeno da doença, a partir de suas distinções na língua inglesa, que o denomina disease, illness e sickness, correspondendo às distintas realidades da doença que interagem entre si: a realidade biológica, a subjetiva e a sociocultural.

A análise de Zémpleni (1994) reafirma a importância dessas formulações, por estas recuperarem, na década de 70, a distinção de perspectivas, como aquela entre a "doença do médico" e a "doença do doente", que havia sido estabelecida em 1936, por R. Lériche, na Encyclopédie Française. Embora ressalte a coragem da formulação de Lériche que confrontava a ideologia médica, Clavreul (1978) nega a possibilidade de haver uma "doença do doente", no âmbito da "ordem médica". Não é possível, segundo o autor, escapar da medicalização da doença do doente.

Na perspectiva de diferenciar o discurso de quem atende e de quem é atendido, buscamos entender a representação da violência dos profissionais da saúde e como essa representação opera no tratamento ao corpo ferido por atos violentos, buscando analisar a própria construção da noção de violência no campo da Saúde.

Não partimos, assim, de uma noção a priori de violência, mas a questão é considerada um fenômeno contextual: um ato não é violento em si, mas o é 
porque a coletividade à qual está referido assim o considera. Trata-se, ainda, de um fenômeno relacional, no qual estão em jogo, pelo menos em princípio, sujeitos - a vítima e o agressor (e os que deles "cuidam") - situados em relações sociais que lhes dão o sentido, a partir do contexto social e cultural onde se manifesta.

Diferenciando agressividade e violência, Costa (1986) afirma que nem todo ato agressivo é violento. Delimita a violência a partir do fato de que a vítima ou o observador reconhecem no agressor o desejo de destruição. A inclusão da figura do observador nessa delimitação introduz um terceiro elemento, passo importante na análise, que requer que se considerem não apenas os atores no ato (ou na relação) de violência e o lugar que ocupam, mas também a questão - eminentemente social - do reconhecimento desse ato como tal. Além disso, o ato violento, por assim se constituir numa relação, pode não ser reconhecido pela vítima, quando esta é objeto de uma violência simbólica, como define Bourdieu (1999). Segundo esse autor, essa forma de violência ocorre quando o sujeito violentado internaliza como legítimos os mecanismos da violência e não os reconhece como tal, fazendo seu o discurso do outro.

A naturalização do ato violento pode implicar sua repetição cíclica sobre a mesma vítima; ou, pela impossibilidade de se sair do circuito de uma relação violenta, a vítima pode fazer outras vítimas, tornando-se agressor, como acontece freqüientemente nos casos de violência contra crianças, perpetrada por vítimas anteriores. Essa identificação perversa foi percebida por Soares (1996), que ressalta a fusão que se opera entre vítima e agressor, o que reafirma o entendimento da violência como um mecanismo relacional e aponta para a necessidade de se trabalhar, no atendimento, todos os lados dessa relação. Esse circuito, que marca as relações violentas, inclui não apenas vítima e agressor, mas também aqueles que deles cuidam no âmbito profissional. É na análise do universo simbólico que ordena as relações implicadas nos atos violentos que procuramos entendê-los ${ }^{8}$.

\section{Os Caminhos da Pesquisa}

O atendimento de emergência é organizado por plantões, divididos em sete equipes diferentes. $\mathrm{O}$ turno de cada equipe corresponde a um plantão diurno e outro noturno, em dias diferentes. Assim, a descontinuidade no contato com o paciente é descrita como uma característica do trabalho na emergência ${ }^{9}$. 
Quando iniciamos o trabalho de campo "sobre o NAVV", com os profissionais de uma das equipes de plantão, percebemos que os médicos da emergência, responsáveis pelo atendimento, nas distintas especialidades, desconheciam o NAVV ou, quando tinham ouvido falar, não o reconheciam como locus de sua atuação. Mencionam como um problema a falta de orientação sobre o que fazer nos casos de violência que atendem. Há o reconhecimento generalizado da necessidade de um encaminhamento dos casos, para além do atendimento médico. A atribuição médica é estritamente a dos procedimentos médicos para cuidar do corpo ferido: curativos, suturas, medicação, analgesia, cirurgia... Se alguma atenção é devida a esses casos, extrapola o atendimento médico na emergência.

Em casos de evidência ou suspeita de violência, em que o paciente se reconhece como vítima, depois do atendimento médico, pode-se encaminhar o paciente para avaliação psiquiátrica. A psiquiatria ocupa a posição de resolver, sempre no âmbito médico, o que não diz respeito mais ao corpo, pensado biologicamente, em termos do funcionamento normal ou patológico das funções vitais (CANGUILHEM, 1995). Um dos cirurgiões declarou que encaminhava para a psiquiatria porque não havia psicólogos na emergência, apenas no setor da internação do hospital. A questão é saber se não há, de fato, psicólogos a quem possam recorrer nesses casos ou se trata da exclusão desse profissional do circuito do atendimento em saúde, na perspectiva da atuação médica na emergência.

O atendimento à emergência engloba os casos considerados de violência, registrados pelo NAVV. A leitura dos médicos entrevistados até agora, sobre o que são casos de violência, não se confunde com aqueles classificados como agressões nos protocolos do NAVV ${ }^{10}$. No discurso médico, a "violência" é associada com aquela que se passa no âmbito doméstico e familiar. Essa categoria se delimita pela identificação de alguma fragilidade na figura da vítima: mulher, criança, idosos. A tendência é reconhecer na figura da vítima alguém passível de sofrer $\mathrm{o}$ ato violento, por corresponder a um lugar definido de antemão como lugar de vulnerabilidade. As vítimas de ferimentos por armas de fogo ou armas brancas não se enquadram na categoria de vítimas de violência que requeiram algum encaminhamento especial. Ainda que se reconheça um aumento da incidência dessas formas de agressão, estas não são problematizadas na acepção de violência, por configurarem ocorrências identificadas com a própria razão de ser da emergência, desde sempre, tendo, portanto, um sentido de problema social estrutural; e, além disso, porque as vítimas - em sua maioria, homens e jovens - não são representadas como tais. 
Essa identificação da violência que chega à emergência como violência doméstica ou familiar corresponde à própria entrada da questão no campo da Saúde, a partir da ação de movimentos sociais pelos direitos da mulher e da criança, que nomeou como violência e instituiu socialmente como abuso e violação de direitos, práticas naturalizadas no contexto hierárquico das relações de gênero e de idade.

A proposta de um atendimento interdisciplinar à vítima de violência aparece, assim, dissociada do atendimento aos corpos feridos no âmbito da emergência. Há um descompasso entre a iniciativa de criar o NAVV, como modalidade de atenção à violência e o atendimento em saúde na emergência, em duplo sentido: pela própria organização do trabalho em plantões e, sobretudo, pela racionalidade que preside o trabalho na emergência, fundada no modelo biomédico. São duas formas de lidar com a questão do atendimento à violência que correm paralelas, cujas diferenças as tornam difíceis de compatibilizar.

Visto da perspectiva do trabalho na emergência, o NAVV opera como um banco de dados, sem vinculação direta com o caminho percorrido nesse âmbito pelo paciente que chega ao hospital. Os médicos fazem seu trabalho alheios à atuação do NAVV, como sempre fizeram nos pronto-socorros.

O foco da pesquisa etnográfica deslocou-se, assim, do NAVV para o atendimento de emergência, independentemente da razão que levou o paciente ao hospital, por ser este o âmbito da intervenção biomédica sobre o corpo objeto de nossa indagação inicial. $\mathrm{O}$ interesse pela emergência aprofundou-se pela constatação de que esse atendimento constitui caso exemplar de concretização da racionalidade biomédica no trabalho médico.

\section{O Atendimento Médico na Emergência: a identificação}

Atuar dentro da estrita racionalidade biomédica (CAMARGO, 1992, 1997) é precisamente o que vincula os médicos ao atendimento na emergência, quando formulado como uma escolha. Ele é considerado uma prova necessária de aprendizado técnico, pela qual todo médico deveria passar:

“A emergência médica é um eterno aprendizado e se eu tivesse o poder de fazer uma lei, todo mundo trabalharia na emergência, porque é ali que você consegue lapidar, atualizar, conhecer, aprender, divulgar o que você faz como profissional" (neurologista). 
Depois desse aprendizado necessário, a permanência na emergência, entretanto, requer o que foi definido como identificação com o trabalho na emergência: "Vou fazer uma comparação com o esporte de adrenalina: você acaba se identificando com aquilo e faz bem para você" (neurologista).

"Eu gosto do atendimento de emergência, porque é um atendimento que não é muito rotineiro, você pegar pacientes todo dia diferentes, um atendimento imediato, tem que estar racionando rápido, tomando as condutas rapidamente. Não é que nem paciente de ambulatório, paciente chega, 'estou com uma dor aqui', você pega, o paciente volta daí a quinze dias, é mais graduado. Aqui não tem rotina, você tem um retorno... você tem que resolver as coisas mais rapidamente" (cirurgião geral).

É precisamente o caráter dinâmico, não rotineiro, imediato, desafiante, prova de competência técnica o que identifica o médico com o trabalho na emergência. Nos casos de doença aguda, a destreza e a precisão necessárias na elaboração do diagnóstico são identificadas como o desafio desse trabalho.

"Eu acho que, de uma maneira geral, é o desafio, o desafio de você colocar para fora aquilo que você acha que tem, acredita que está bem informado e que você é capaz de fazer alguma coisa [...]. É mais ou menos isso, é o desafio, os esportes radicais. O indivíduo, cada vez que vai fazer um esporte radical, ele quer mais, ele quer mais, então, ele tem um perfil para aquilo ali. A emergência, para mim, também é a mesma coisa, é um desafio. Não o desafio da vida e da morte, mas o desafio daquilo que você se propõe, em ter uma qualificação, uma formação e por isso em prática [...]. Se você tem esse perfil para se identificar com essa descarga de adrenalina, é gratificante para quem faz" (neurologista) ${ }^{11}$.

O foco está primordialmente no procedimento, no trabalho como técnica, aplicada sobre um corpo, em sua dimensão biológica, pensado como objeto de intervenção. O risco de vida iminente afasta a noção de doença (e aproxima a de morte). Não obstante, há implícita uma concepção ontológica da doença (CANGUILHEM, 1995), pensada como uma entidade com existência própria, independente do doente ${ }^{12}$.

Ouvimos que doença é aquilo que se vê. Essa fala, entretanto, veio da psiquiatra, ao comentar que as perturbações mentais não são consideradas 
doença pelos médicos de especialidades clínicas ou cirúrgicas e que, por isso, os pacientes psiquiátricos não são levados a sério, sendo freqüentemente objeto de comentários jocosos.

O trabalho médico na emergência (exceto os casos agudos) incide principalmente sobre ferimentos, que requerem procedimentos, independentemente do que provocou esses ferimentos. Foi expresso como indiferente ao tratamento, a razão pela qual o paciente está ferido. O locus da intervenção médica é o corpo biológico, sobre o qual se aplica um procedimento. Qualquer problema que extrapole esse âmbito de atuação não é reconhecido como problema médico.

Para além da especialidade médica, o trabalho médico na emergência reveste-se de um caráter cirúrgico, identificado com a razão de ser do trabalho médico na emergência:

"Cirurgia depende muito de você também, paciente chega aqui, você resolve o problema dele, vai e opera, daí a umas horas o paciente está bem. A coisa é imediata, é mais dinâmica. A cirurgia é mais dinâmica. $\mathrm{O}$ atendimento na emergência, você está aqui, pode estar tudo tranqüilo, de repente... Sexta à noite, eu estava aqui, aquele frio, não tinha ninguém aqui, aí, de nove até as dez chegaram quatro baleados!” (cirurgião geral).

"Eu entrei (em medicina) com a intenção de fazer cirurgia, porque é uma coisa muito resolutiva. Não precisa pensar. Não é que não precisa pensar, é óbvio que o cirurgião pensa, mas a técnica é predominante. A técnica é essa, a melhor técnica usada, você chega, faz e é isso. Se você tem uma boa técnica, você é um bom cirurgião. Então, não exigia mais nada além disso" (psiquiatra).

O atendimento é descrito como um momento mágico: todos convergem. $A$ despeito de as relações interpessoais (entre a equipe de saúde) serem descritas como complicadas,

"No momento da urgência, da emergência, nenhum problema, o doente é supremo. O cliente que está em risco de vida é supremo, tem que ser feito tudo por ele. [...] Eu posso não gostar de você, [...] mas na hora do pega-prácapá, do sufoco ali, isso aí é passado por cima, tanto de você quanto de mim. [...], a integração (da equipe) na hora do fato é total. Depois, cada um toma o seu rumo e cada um leva as suas mágoas e frustrações" (neurologista). 
A necessidade de ajuda iminente ao paciente "ali, precisando de você" é um dos aspectos que tornam gratificante o trabalho na emergência. Neste caso, não é a relação entre médico e paciente que está em jogo, mas o profissional como figura imprescindível, central no atendimento de urgência e emergência.

"Todo cirurgião adora emergência. Na maioria das vezes, você pega pacientes graves, pacientes que estão precisando de você, ali, naquele momento. Tem um retorno muito grande, imediato com os pacientes. Eles realmente estão necessitando de alguém. Eu gosto de emergência" (cirurgião geral).

A descontinuidade no contato com o paciente, entretanto, é expressa como fonte de frustrações.

"Você não tem aquilo que você tem no consultório, que é o familiar te ligando, o paciente voltando para falar com você, para te dar satisfação do que está acontecendo, às vezes para dizer que aquilo que você está fazendo não está dando certo. Na emergência você é um mero funcionário, um mero profissional que é pago para fazer o pronto atendimento, a urgência e a emergência médica. [...] E vivemos num contexto em que o retorno para esse profissional noventa por cento das vezes não existe, (retorno) de satisfação, de saber como esse paciente evoluiu. Eu posso salvar uma vida hoje aqui, amanhã eu não sei como esse paciente está mais" (neurologista).

Não se trata propriamente de uma demanda de vínculo entre o médico e o paciente, mas do profissional que se ressente da falta de reconhecimento de seu trabalho, de retorno, que advém do contato com o paciente. O retorno reconhecido no depoimento anterior refere-se ao caráter imediato do trabalho cirúrgico, cujo produto se olha e se vê. O que o profissional (não-cirurgião) expressa é a necessidade de reconhecimento social de si como profissional.

O discurso da enfermeira sobre o trabalho médico, que traz implícita a comparação com seu próprio trabalho, configurando uma forma de autovalorização, define esse trabalho como uma intervenção técnica sobre a doença, ainda que seu depoimento não se restrinja à situação de emergência: "O médico faz o diagnóstico e dá o tratamento prescrito para a doença diagnosticada, independentemente das características do paciente. É um tratamento padrão". 


\section{A Lógica de Prioridades na Emergência}

A definição de prioridades é uma questão intrínseca à emergência: "tem situações angustiantes, tem vários pacientes e não tem médico e todos precisando de você...".

"Os pacientes já vêm triados pelo socorrista, o resgate faz uma triagem prévia. ${ }^{13}$ Aqui fica mais fácil fazer uma segunda triagem, digamos assim. Tem pacientes que estão graves, mas podem aguardar um pouco e tem aqueles que têm que ter atendimento imediato ${ }^{14}$. [...] Você atende logo criança [...] tem também aquele negócio do mais grave, mas uma das orientações é você atender aquele que tem prognóstico melhor. Por exemplo, entre dois pacientes graves, só que um é muito mais grave, está com traumatismo craniano grave, traumatismo no tórax, traumatismo em abdômen, realmente grave, mas tem outro que tem um só traumatismo, ele também está precisando de você, você atende ele, não vai atender o mais grave na verdade, porque ele tem um prognóstico muito ruim" (cirurgião).

A naturalização dos mecanismos de definição de prioridades é bastante clara e já foi ressaltada nos estudos sobre atendimento de emergência (SKABA 1997, DESLANDES 2002). Fazem-se escolhas, com base no que se chama de "bom senso": crianças em primeiro lugar; idosos sempre citados como nãoprioritários, quando comparados com jovens e crianças e assim por diante.

"Por exemplo, isso é uma coisa que é básica, se você tem um senhor de 80 anos e uma criança de sete, no mesmo acidente, quem que você vai ver... É uma questão de bom senso. [...] Chegou um monte de baleado, quem você vai ver? Quem tem alguma chance de ser salvo; quem tem menos balas, quem está numa condição melhor, quem é mais jovem, criança principalmente. Chega um baleado com dois tiros e o outro com vinte tiros... você fica na dúvida, que eu vou fazer? Vamos tentar salvar quem está mais grave, quem tomou vinte tiros? Mas esse que tomou dois tiros, que a chance de sobreviver é maior, acho que tem que investir mais nele [...]. Se chegar uma criança, você vai direto na criança, porque é a que maior chance de ir para frente" (psiquiatra).

Os profissionais orientam-se por princípios éticos médicos, regulamentados internacionalmente, segundo os quais não se hierarquizam os pacientes, manifestação clara do individualismo igualitário ocidental. Situamse, portanto, entre, de um lado, a lealdade a princípios que se pretendem 
universalmente aplicáveis e objetivamente definidos (nos casos de "salvar vidas") e, de outro, situações concretas, nas quais estão em jogo sujeitos concretos, médicos e pacientes, com suas crenças, valores e concepções particulares do mundo que os cerca.

Não tardou muito para que os profissionais começassem a se manifestar como sujeitos concretos. Nos casos de violência, não é fácil para eles atender agressores, cuja atitude contraria seus valores morais. As agressões são identificadas com a ação de algum elemento externo que as desencadeia álcool ou outro tipo de "droga" -, ao mesmo tempo em que identificam uma predisposição interna a esses agentes externos. "Bêbado é o único paciente que incomoda, que me incomoda tratar; atrapalha, traz problema, problema que ele mesmo criou" (cirurgião).

Expressam, assim, o incômodo de tratar de pacientes que tentaram suicídio: "por que se ocupar de quem não quer viver: por que não morreu de uma vez?".

\section{A Oposição entre Emergência e Atenção à Violência}

No âmbito das práticas hospitalares de emergência, portanto, não é fácil entrever a possibilidade de haver lugar para a perspectiva do doente, a "doença do doente", de Lériche. Ela, na melhor das hipóteses será, como Clavreul ressaltou, medicalizada.

A especificidade da emergência ou urgência, pelo risco iminente de vida em que se encontram os pacientes, acentua a exigência de habilidades técnicas com base no conhecimento biomédico. $\mathrm{O}$ atendimento alimenta a lógica circular, que identifica o paciente com seu corpo biológico e, em contrapartida, concebe o médico como um técnico que intervém sobre esse corpo.

Pretendemos argumentar que a identificação com o trabalho da emergência, acima descrita, não destitui o médico de sua subjetividade, mas institui posições objetivas e subjetivas, que, ao excluir determinadas formas de manifestações subjetivas, instituem outras, que o predispõem para esse trabalho. O processo se inicia na formação profissional, a partir da construção do conhecimento sobre o corpo, a saúde e a doença, que não contempla as questões epistemológicas implicadas no fato de que, ao pôr em prática o conhecimento adquirido, estabelece-se um contato entre o profissional e o paciente, intrínseco 
ao atendimento médico. A prática que decorre dessa formação envolve o nãoreconhecimento do processo interativo implícito no contato entre médico e paciente, como condição do exercício de um saber concebido como técnica.

Toda uma organização sustenta essa racionalidade, no espaço físico, na organização do trabalho e nos ritos de instituição, como demonstra o trabalho de Deslandes (2002), ainda que essa ordenação, como qualquer universo de relações, comporte fissuras e ambigüidades.

No contexto da emergência, dada a forma como se dá a identificação dos profissionais com esse atendimento, não há como não medicalizar a violência. Parece ser fora desta configuração do atendimento que o problema da violência pode ser tratado como questão relacional e contextual É o que explicitam os profissionais da saúde, agentes desse microcosmo exemplar da ordem médica que são os hospitais de emergência.

\section{Referências}

ALBANO, C.; MONTERO, P. Anatomia da violência. In: LUZ, M.T.(Org.). O lugar da mulher. Rio de Janeiro: Graal, 1982. p. 107-26.

ARDAILLON, D.; DEBERT, G.G. Quando a vítima é mulher. Brasília: Conselho Nacional dos Direitos da Mulher, 1987.

BIANCARELLI, A. Violência deve ser monitorada como doença. Folha de São Paulo, São Paulo, 10 fev. 2002. Caderno C6.

BOURDIEU, P. A dominação masculina. Rio de Janeiro: Bertrand Brasil, 1999.

CAMARGO JUNIOR, K.R. A biomedicina. Physis, Rio de Janeiro, v. 7, $n$. 1, p. 45-68, 1997.

. (Ir)Racionalidade médica: os paradoxos da clínica. Physis, Rio de Janeiro, v. 2, n.1, p. 203-228, 1992.

CANGUILHEM, G. O normal e o patológico. Rio de Janeiro: Forense Universitária, 1995

CLAVREU, J. L'ordre médical. Paris: Ed. du Seuil, 1978.

COSTA, J.F. Violência e psicanálise. Rio de Janeiro: Graal, 1986. (Biblioteca de Psicanálise e Sociedade, 3). 
DESLANDES, S.F. O atendimento a vítimas de violência na emergência: "prevenção numa hora dessas?". Ciência \& Saúde Coletiva, Rio de Janeiro, v. 4, n.1, p. 81-94, 1999.

- Frágeis deuses: profissionais da emergência entre os danos da violência e a recriação da vida. Rio de Janeiro: FIOCRUZ, 2002. (Coleção Antropologia e Saúde, 8).

DUARTE, L.F.D. Investigação antropológica sobre doença, sofrimento e perturbação: uma introdução. In: DUARTE, L.F.D.; LEAL, O.F. (Org.). Doença, sofrimento e perturbação: perspectivas etnográficas. Rio de Janeiro: FIOCRUZ, 1998. p. 9-27.

FOUCAULT, M. O nascimento da clínica. Rio de Janeiro: Forense Universitária, 1977.

GUERRERO, R. La violencia desde la perspectiva de la salud pública. In: BRICEÑO-LEON, R. (Coord.). Salud y Equidad: una mirada desde las ciencias sociales. Rio de Janeiro: Fiocruz, 2000. p. 147-156.

GREGORI, M.F. Cenas e queixas: um estudo sobre mulheres, relações violentas e prática feminista. São Paulo: Paz e Terra/ANPOCS, 1993.

GROSSI, M. 1994. Novas/velhas violências contra a mulher no Brasil. Estudos Feministas, Rio de Janeiro: $\mathrm{n}^{\circ}$ especial, p. 473-483, 1994.

HELMAN, C.G. Cultura, saúde e doença. 2.ed. Porto Alegre: Artes Médicas, 1994.

JACQUEMOT, A. As representações médicas e leigas da urgência/emergência. In: REUNIÃO DE ANTROPOLOGIA DO MERCOSUL, 4., 2001, Curitiba. Anais... 2001.

MATTA, R. da. Os discursos da violência no Brasil. In: . Conta de mentiroso: sete ensaios de antropologia brasileira. Rio de Janeiro: Rocco, 1994. p. 175-197.

MINAYO, M.C.S. A violência social sob a perspectiva da saúde pública. Cadernos de Saúde Pública, Rio de Janeiro, v. 10, p. 7-18, 1994.

MINAYO, M.C.S.; SOUZA, E.R. É possível prevenir a violência?: reflexões a partir do campo da saúde pública. Ciência e Saúde Coletiva, Rio de Janeiro, v. 4, n.1, p.7-32, 1999. 
OLIVEIRA, E.M. Violência contra a mulher: uma questão de gênero. Acta Paulista de Enfermagem, São Paulo, v. 13, nº especial, p.171-180, 2000.

PAUL, N. Incurable suffering from the "hiatus theoreticus"?: some epistemological problems in modern medicine and the clinical relevance of philosophy of medicine. Theoretical Medicine and Bioethics, Dordrecht, v. 19, p. 229-251, 1998.

PONTES, H. Do palco aos bastidores: o SOS Mulher e as práticas feministas contemporâneas. 1986. Dissertação (Mestrado)-Instituto de Filosofia e Ciências Humanas, Universidade Estadual de Campinas, Campinas, 1986.

SAFFIOTTI, H. O estatuto teórico da violência de gênero. In: SANTOS, J.V.T. (Org.). Violência em tempo de globalização. São Paulo: HUCITEC, 1999. p. 142-63.

SARTI, C.A. O reconhecimento do outro: uma busca de diálogo entre ciências humanas e ciências da saúde. 2003. Tese (Livre-Docência)-Departamento de Medicina Preventiva, Universidade Federal de São Paulo, São Paulo, 2003.

SARTI C. A família como espelho: um estudo sobre a moral dos pobres. $3^{\text {a }}$ ed. São Paulo: Cortez, 2005.

SKABA, M.M.V.F. $O$ vício da adrenalina: etnografia da violência em um hospital de emergência. 1997 (Dissertação)-Escola Nacional de Saúde Pública, Rio de Janeiro, 1997.

SOARES LE. Juventude e violência no Brasil contemporâneo. In: NOVAES, R.; VANNUCCHI, P.(Orgs.). Juventude e sociedade: trabalho, educação, cultura e participação. São Paulo: Fundação Perseu Abramo, 2004. p. 130-159.

SOARES, L.E. et al. Violência e política no Rio de Janeiro. Rio de Janeiro: ISER/Relume Dumará, 1996.

SUAREZ, M.; BANDEIRA, L. (Orgs.). Violência, gênero e crime no Distrito Federal. Brasília: UnB, 1999.

VELHO, G. Violência, reciprocidade e desigualdade: uma perspectiva antropológica. In: VELHO, G.; ALVITO, M.(Orgs). Cidadania e violência. Rio de Janeiro: UFRJ/FGV, 1996. p.10-24.

ZALUAR, A. Violência e crime. In: MICELI, S.(Org.) O que ler na ciência social brasileira. São Paulo: Sumaré: ANPOCS/CAPES, 1999. 


\section{ZEMPLÉNI, A. A “doença” e suas “causas”. Cadernos de Campo, São Paulo, n.4, p.137-163, 1994.}

\section{NOTAS}

* Doutora em Antropologia Social pela USP; professora Livre-docente no Departamento de Medicina Preventiva da Universidade Federal de São Paulo/Escola Paulista de Medicina. Endereço eletrônico: csarti@uol.com.br.

${ }^{1}$ A primeira versão deste texto foi apresentada no $27^{a}$ Encontro Anual da ANPOCS (Associação Nacional de Pesquisa e Pós-Graduação em Ciências Sociais), Caxambu, 21 a 25 de outubro de 2003, no Grupo de Trabalho "Pessoa e corpo: novas tecnologias biológicas e novas configurações ideológicas".

${ }^{2}$ Esse projeto, que continua em andamento, foi formulado e está sendo realizado em colaboração com Rosana Machin Barbosa, também professora no DMP-UNIFESP, junto a uma equipe de bolsistas de Iniciação Científica, integrada, em seu início, por Patrícia da Rocha Figueredo, Marcelo Mendes Suarez e Rubens Luis Folchini, do Curso de Graduação em Medicina da UNIFESP. Os dados, aqui apresentados e trabalhados, foram coletados por toda a equipe. Iniciamos a pesquisa de campo, depois da aprovação do projeto pelo Comitê de Ética em Pesquisa (CEP) da UNIFESP, atendendo às exigências da Resolução 196/96 do Conselho Nacional de Saúde.

${ }^{3}$ Agradeço a Regina André Rebollo pela indicação deste texto, discutido em sua aula no Curso de Pós-graduação "Ciências Humanas e Saúde”, que realizamos no primeiro semestre de 2003, na UNIFESP.

${ }^{4}$ Ou Biomedicina, como uma das "racionalidades médicas" (CAMARGO JR., 1992 e 1997).

${ }^{5}$ Tradução minha. O texto original é: "Chacun de nous est trop solidaire du discours médical pour ne pas en épouser d'avance les raisons" (p. 27).

${ }^{6}$ Cf. Resolução da 49a Assembléia da OMS, em 1996. A OPAS já havia decretado em 1993 que a violência era prioridade de saúde pública nas Américas (GUERRERO, 2000).

${ }^{7}$ Em entrevista ao jornal Folha de São Paulo, o epidemiologista João Yunes declarou que a violência, como problema de saúde pública, deve ser "monitorada como uma doença infectocontagiosa" (apud BIANCARELLI, 2002). 
${ }^{8}$ Tal como argumentado em trabalho anterior sobre o universo moral dos pobres (SARTI, 2005), na quebra da reciprocidade, princípio fundador de sua moralidade, emerge a justificativa moral para atos violentos. A relação entre a quebra de reciprocidades e a violência encontra-se igualmente na reflexão de Da Matta (1994) e de Velho (1996).

${ }^{9}$ As reflexões, aqui apresentadas, resultam da primeira fase do trabalho de campo. Baseiam-se em dados de observação do atendimento na emergência e da dinâmica de funcionamento do pronto-socorro; e em entrevistas não-estruturadas com profissionais (enfermeiras e médicos) e com a direção do hospital.

${ }^{10}$ A classificação do NAVV segue a Classificação Internacional das Doenças (em sua décima versão, conhecida pela sigla CID-10), o que coloca, em si, o problema da lógica de construção dessa classificação.

${ }^{11}$ O trabalho de Skaba (1997) sobre o atendimento em hospitais de emergência intitula-se precisamente "O vício da adrenalina", a partir da fala de uma enfermeira. Esse aspecto é reconhecido nos trabalhos sobre emergência em geral (DESLANDES, 2002).

${ }^{12} \mathrm{O}$ caráter implícito da concepção de doença na racionalidade biomédica e a ausência de discussão a esse respeito são aspectos importantes ressaltados por Camargo Jr. (1992, 1997), para quem a imprecisão na concepção de doença existe desde a formação profissional do médico.

${ }^{13}$ Existem no resgate aos pacientes (APH - Assistência Pré-Hospitalar) critérios de prioridade, conforme o que consideram a gravidade da doença (o "risco de vida"). Assim, por exemplo, infarto, AVC (acidente vascular cerebral) ou embolia pulmonar são prioridades 1, enquanto diabete, quedas ou pressão alta são prioridade 2 .

${ }^{14}$ Os médicos seguem um protocolo elaborado por um colegiado norte-americano de cirurgiões, o ATLS (Advanced Trauma Life Support), para a triagem dos pacientes, também objeto desta investigação. 


\section{ABSTRACT}

\section{Emergency Care for Bodies Injured by Violent Acts}

The underlying question in this article relates to the limits and possibilities of care for victims of violence as provided by health services, specifically by emergency departments. The initial problem is that specialized care for these cases requires interdisciplinary and multi-professional action, distinct from that proposed during the biomedical training of health professionals as a whole and especially physicians and nurses. Beginning with an ethnographic study of a public emergency hospital in the city of São Paulo, the article then seeks to analyze the concepts of body and violence adopted by these professionals, underlying their care for bodies injured by violent acts, within the characteristics of these services. The focus is on concepts and practices in a healthcare context characterized by the displacement of subjectivity both in patients and health professionals, illustrated by emergency services, with a discussion on the implications for treatment of victims of violence.

Key words: Healthcare practices; biomedicine; care for violence; emergency. 